\title{
Current aspects of polycystic ovary syndrome: A literature review
}

\author{
Victor Hugo lopes de Andrade ${ }^{1}$, Ana Maria Oliveira Ferreira da Mata ${ }^{1}$, Rafael Soares Borges ${ }^{2}$, Danylo Rafhael Costa-Silva ${ }^{2}$, \\ Luana Mota Martins ${ }^{2,3}$, Paulo Michel Pinheiro Ferreira ${ }^{1,3}$, Lívio César Cunha-Nunes ${ }^{1,3}$, Benedito Borges da Silva ${ }^{1,2,3 *}$ \\ ${ }^{1}$ Postgraduate Program in Pharmaceutical Sciences, Universidade Federal do Piaú (UFPI), Teresina, PI, Brazil \\ ${ }^{2}$ Department of Gynecology, UFPI, Teresina, PI, Brazil \\ 3Postgraduate Program of the Rede Nordeste de Biotecnologia (Renorbio), UFPI, Teresina, PI, Brazil
}

\begin{abstract}
SUMmaRY
Study conducted by the Postgraduate Program in Pharmaceutical Sciences, Teresina, PI - Brazil

Article received: $1 / 19 / 2016$ Accepted for publication: $1 / 30 / 2016$

*Correspondence: Address: Av. Elias João Tajra, 1260 Teresina, PI - Brazil Postal code: 64049-300

Polycystic ovary syndrome (PCOS) is a heterogeneous endocrine disorder with variable prevalence, affecting about one in every 15 women worldwide. The diagnosis of polycystic ovary syndrome requires at least two of the following criteria: oligoovulation and/or anovulation, clinical and/or biochemical evidence of hyperandrogenism and morphology of polycystic ovaries. Women with PCOS appear to have a higher risk of developing metabolic disorders, hypertension and cardiovascular disorders. The aim of this article was to present a review of the literature by searching the databases Pubmed and Scielo, focusing on publications related to polycystic ovaries, including its pathogenesis, clinical manifestations, diagnosis and therapeutic aspects, as well as its association with cardiovascular and arterial hypertensive disorders.
\end{abstract} beneditoborges@globo.com
Keywords: polycystic ovary syndrome, hyperandrogenism, cardiovascular disorders, arterial hypertension.

\section{INTRODUCTION}

Polycystic ovary syndrome (PCOS) is a common gynecological endocrine disorder of unknown etiology, with a prevalence ranging from 8.7 to $17.8 \%$ in women of reproductive age. ${ }^{1}$ Evidence suggests that PCOS phenotype may vary widely and is most commonly observed in the post-pubertal period. ${ }^{2}$ Despite a diversity of phenotypes, women with PCOS are characterized by polycystic ovaries, chronic anovulation, hyperandrogenism and gonadotropin abnormalities. ${ }^{3,4}$

In addition to the characteristics that are inherent in PCOS, it is a common occurrence of metabolic and hormonal abnormalities associated with obesity, type 2 diabetes mellitus and dyslipidemia. ${ }^{5}$ A combination of these characteristics lead to metabolic syndrome. ${ }^{6}$ The variety of metabolic disturbances in PCOS may be related to a higher risk of developing cardiovascular disease. ${ }^{7}$ This fact may explain a predisposition to arterial hypertension in women suffering from the syndrome. ${ }^{8}$ Although the association between changes in arterial blood pressure and PCOS has still not been fully elucidated, the increased risk of hypertensive state may be explained by insulin resistance and hyperandrogenism, even when adjusted for age, body mass index and other anthropometric parameters. ${ }^{9}$

The study of PCOS is one of the most important topics in female reproductive endocrinology, subject that has the experience of our research group with studies in rats in persistent estrus mimicking state of chronic anovulation. ${ }^{3}$ Although the syndrome has been widely investigated, its definition and pathophysiological aspects are still highly controversial. Therefore, the aim of the current study was to conduct a non-systematic review of published literature through PubMed and SciELO search. Publications were related to polycystic ovaries, including the pathogenesis, clinical manifestations, diagnosis and therapeutic aspects of the disease, as well as its association with cardiovascular disease and arterial hypertension. The current study may also contribute to raise awareness about the risk of hypertension in patients with polycystic ovary syndrome.

\section{EtIoLOGY AND PATHOPHYSIOLOGY}

Polycystic ovary syndrome is a chronic disorder with unknown etiology that was first described in 1935 by Stein 
and Leventhal. It is a reproductive, heterogeneous and metabolic disorder. ${ }^{10}$ The prevalence of the disorder ranges from 8.7 to $17.8 \%$ in women of reproductive age. ${ }^{1}$ The first clinical manifestations of PCOS are present in adolescence. However, there is evidence that the disease has its origin in the intrauterine environment, indicating genetic involvement. ${ }^{11}$ Some studies including a study by Soter et al., ${ }^{12}$ have demonstrated a definite influence of interleukin- 6 and interleukin-10 gene polymorphisms, interferon-c and transforming growth factor-beta 1 in the development of PCOS, although no clear pattern of inheritance has been identified. ${ }^{12}$ Other causal factors are epigenetic exposures, highlighting the association between intrauterine exposure and maternal androgens and phenotypes related to the syndrome..$^{13}$ Ethnic variations in PCOS may be associated with environmental factors, such as socioeconomic conditions and lifestyle. ${ }^{14}$

Despite a large number of research studies, pathogenesis of PCOS still needs further elucidation. ${ }^{15}$ However, some pathophysiological mechanisms are known, e.g. alterations in the secretion of gonadotropin-releasing hormone, defect in androgen synthesis and development of insulin resistance. ${ }^{16}$ One of the numerous theories proposed to explain pathogenesis of the syndrome is the disturbance of the hypothalamic-pituitary axis, resulting in disarranged gonadotropin secretion by the hypothalamus with a consequent elevation of luteinizing hormone (LH) levels and normal and/or low follicle-stimulating hormone (FSH) levels. ${ }^{14}$

A number of studies have also indicated that insulin resistance is the key pathophysiological element for development of the syndrome. Insulin acts synergistically with LH to increase androgen production in the theca cell of the ovary. ${ }^{17}$ Another site for androgen production is the adrenal cortex, due to abnormalities in cortical stereoidogenesis promoted by stimulation of adrenocorticotropic hormone. ${ }^{18}$ And these excess androgen levels, mainly testosterone, androstenedione and dehydroepiandrosterone sulfate, cause premature atresia of ovarian follicles, forming multiple cysts and anovulation with persistent estrogen levels resulting from aromatization of androgens to estrogens without opposition of progesterone and associated with an increased risk of endometrial carcinoma. ${ }^{19,20}$

\section{Clinical manifestations and diagnosis}

In the Rotterdam Consensus, it was defined that at least two of the following three findings are required for diagnosis of PCOS: oligoovulation or chronic anovulation, clinical and/or laboratory evidence of hyperandrogenism, and pelvic ultrasonography indicative of polycystic ovaries. ${ }^{10}$ These criteria recognize that PCOS is a diagnosis of exclusion. ${ }^{21}$ Therefore, to confirm this syndrome, disorders that mimic the clinical characteristics of PCOS must be excluded, such as thyroid disorders, hyperprolactinemia and non-classical congenital adrenal hyperplasia. $^{22}$

Although PCOS has been traditionally considered a disorder that affects women in their reproductive years, clinical manifestations may be observed at menarche. ${ }^{23}$ In addition, clinical complications vary according to different phenotypes, age, ethnicity and body weight. ${ }^{24}$

According to research studies, the classical PCOS phenotype is linked to hyperandrogenism, anovulation and polycystic ovaries. Symptoms usually worsen with time. ${ }^{25}$ Among these characteristics, hyperandrogenism is considered a cardinal element for diagnosing this condition and to define a patient as hyperandrogenic may be of major clinical significance. ${ }^{26}$ The clinical manifestation of hyperandrogenism in these women varies in different ethnic groups, with external manifestations like oily skin, acne, hirsutism, central obesity, and even androgenetic alopecia. $^{22,27}$

The cardiovascular system of women with PCOS is affected, regardless of obesity, due to metabolic disturbance associated with the respective syndrome. ${ }^{28}$ Factors such as dyslipidemia, diabetes and obesity are all potent risk factors for cardiovascular disease, explaining why women with PCOS are more predisposed to hypertension. ${ }^{8}$

\section{PCOS AND HYPERTENSION}

In general, systemic arterial hypertension (SAH) is more common in PCOS patients. A study carried out by Stener-Victorin et al. ${ }^{28}$ showed that the prevalence of hypertension was about $40 \%$ in this group of women. Insulin resistance is a potential determinant of the association between PCOS and hypertension. It plays a central role not only in the development of PCOS, but also in the development of cardiovascular disease. ${ }^{29}$

Researchers have invested in research studies to discover the underlying relationship between hypertension and endocrine disorder. One of the most well-accepted hypotheses is that such alterations are stimulated by insulin resistance. ${ }^{28}$ Some authors demonstrated an inverse association between insulin sensitivity and systolic arterial pressure in the group of women with PCOS. ${ }^{30}$

Insulin resistance leads to hyperinsulinemia and amplification of LH action in theca cells, with a consequent increase in androgen levels (Figure 1). ${ }^{19,20}$ In experimental models, some authors have also demonstrated that the 
adrenal gland of the rat in persistent estrus resembles PCOS. A higher proliferative activity occurred in the reticular zone of the adrenal gland, producer of androgens in humans, in comparison to controls. ${ }^{3}$ Androgen levels may directly regulate the renin-angiotensin system of the proximal renal tubule and increase reabsorption flow rate, thus increasing extracellular volume and blood pressure., ${ }^{7,31}$

A long-term follow-up study carried out by Wild et al..$^{32}$ suggested an increased prevalence of hypertension in patients with PCOS. However, it did not evaluate the association between PCOS syndrome and the increased risk of morbidity and mortality from coronary artery disease. ${ }^{33,34}$ Nevertheless, these results suggest that women with polycystic ovary syndrome should be screened for hypertension at a younger age. ${ }^{35}$

\section{Animal model}

A study of women with polycystic ovaries has some ethical limitations. Therefore, there has been a search for appropriate experimental models that mimic PCOS. ${ }^{36}$ During the last decades, researchers have used diverse animal models, such as rats, mice, hamsters, guinea pigs and subhuman primates to study the reproductive cycle, ovarian morphology and hormonal changes. ${ }^{37}$ However, the animal model that has the morphology and endocrinology most similar to humans is the rat. ${ }^{38}$

Rats are polyestrous animals, i.e., these animals have regular and consecutive estrous cycles, manifested by morphological changes in the ovaries, uterus, vagina and mammary glands. These cycles last from 4 to 6 days and are easily observed, including proestrus, estrus, metaestrus and anestrus, with a mean pregnancy period of 21 days. ${ }^{39,40}$

Nevertheless, interruption of the rat estrous cycle, characterized by persistent vaginal keratinization or persistent estrus, is different from the short period of sexual receptivity named estrus or heat. The rat model was more widely studied by Barraclough in 1961, who characterized the period of most intense hypothalamic sensitivity. That author used only a subcutaneous injection of androgen (testosterone propionate at a dose of $1.25 \mathrm{mg}$ ). Thus, a simple s.c. injection of $1.25 \mathrm{mg}$ of testosterone propionate administered to female rats during the first 5 days of live induced persistent estrus in all animals. ${ }^{39,41,42}$

These animals in adulthood present anovulation, higher LH secretion, polycystic ovaries and aggressive behavior when in contact with males, thus there is a resemblance to the human condition of polycystic ovary syndrome. ${ }^{18,40}$ Furthermore, rats in persistent estrus may have hypertension, as shown in a study conducted by Gontijo et al. ${ }^{8}$ Those authors showed that rats in persistent estrus had a significant increase in arterial pressure, in comparison to rats in the control group. ${ }^{8}$

\section{TREATMENT}

Regarding treatment, it is recommended to start with aggressive diet/lifestyle modifications which may lead to weight loss, improve anovulation and indirectly cause a reduction in systolic arterial pressure. ${ }^{33}$ If weight loss is insufficient to correct anovulation and decrease arterial pressure, drug treatment should be administered in order

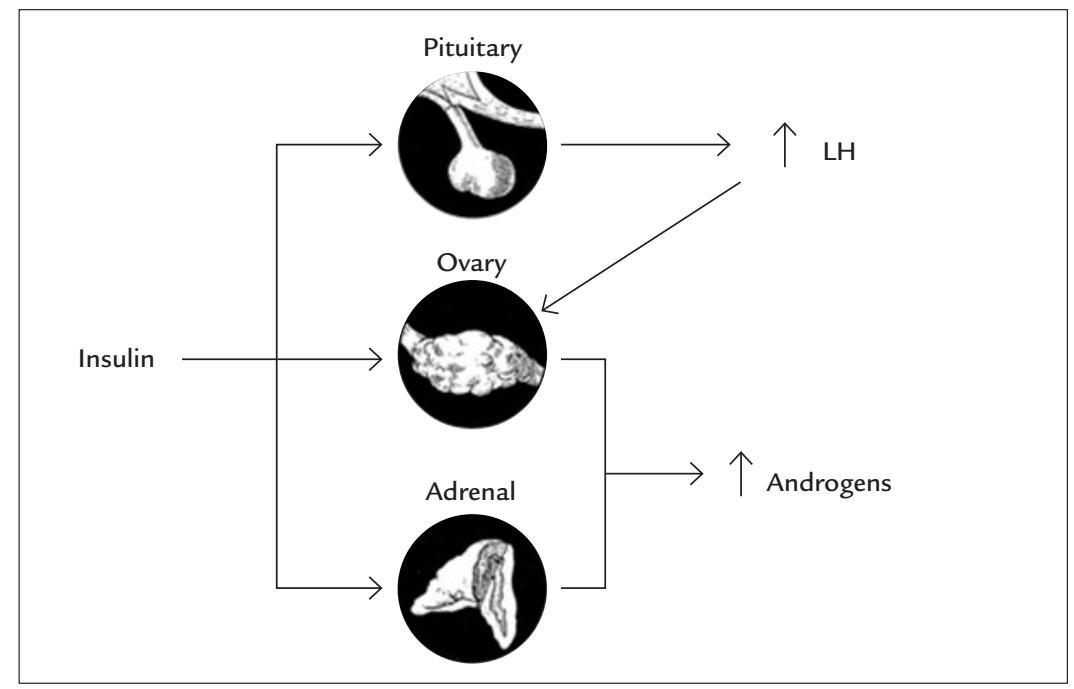

FIGURE 1 The influence of insulin in the amplification of $\mathrm{LH}$ and

increase in androgen levels.

Source: Adapted from Dunaif. ${ }^{19}$ 
to correct the signs and symptoms. Despite a lack of consensus on the treatment of cardiovascular disease in women with PCOS, target therapy for hypertension in the PCOS population is similar to treatment given to patients without the syndrome..$^{25}$

\section{Conclusion}

Women with PCOS, in addition to anovulation and infertility, have an increased risk of developing hypertension and cardiovascular disease in association with metabolic syndrome. The diagnosis of PCOS is fundamentally clinical. Treatment of PCOS is limited to management of signs and symptoms since the etiology of the disorder is unknown. There is a need for further studies to understand the pathophysiology of PCOS and the development of high blood pressure in women suffering from the disorder.

\section{Resumo}

Aspectos atuais da síndrome do ovário policístico: uma revisão da literatura

A síndrome dos ovários policísticos (SOP) é uma desordem endócrina heterogênea com prevalência variável, que afeta cerca de uma em cada 15 mulheres no mundo. O diagnóstico da SOP requer, pelo menos, dois dos seguintes critérios: oligo-ovulação e/ou anovulação, evidência clínica e/ou bioquímica de hiperandrogenemia e morfologia dos ovários policísticos. As mulheres com SOP parecem ter um risco mais elevado de desenvolver distúrbios metabólicos, hipertensão e doenças cardiovasculares. O objetivo deste artigo foi apresentar uma revisão da literatura por meio de pesquisa nas bases de dados PubMed e Scielo, focada em publicações relacionadas com ovários policísticos, incluindo patogênese, manifestações clínicas, diagnóstico e aspectos terapêuticos, bem como associação com doenças cardiovasculares e hipertensão arterial.

Palavras-chave: síndrome do ovário policístico, hiperandrogenismo, distúrbios cardiovasculares, hipertensão arterial.

\section{References}

1. Zueff LFN, Marti ns WP, Vieira CS, Ferriani RA. Ultrasonographic and laboratory markers of metabolic and cardiovascular disease risk in obese women with polycystic ovary syndrome. Ultrasound Obstet Gynecol. 2012; 39(3):341-7.

2. Spritzer PM. Polycystic ovary syndrome: reviewing diagnosis and management of metabolic disturbances. Arq Bras Endocrinol Metabol. 2014; $58(2): 182-7$.
3. da Silva BB, Lopes-Costa PV, dos Santos AR, Pires CG, Borges CS, Gontijo JA. Evaluation of Ki-67 antigen expression. in the zona reticularis of the adrenal cortex of female rats in persistent estrus. Hum Reprod. 2009; 24(3):705-9.

4. Azziz R. PCOS in 2015: New insights into the genetics of polycistics ovary syndrome. Nat Rev Endocrinol. 2016; 12(2):74-5.

5. Connolly F, Rae MT, Späth K, Boswell L, McNeilly AS, Duncan WC. In a Ovine Model of Polycystic Ovary Syndrome (PCOS) prenatal androgens suppress female renal gluconeogenesis. PLos One. 2015; 10(7):e0132113.

6. Costa EC, Soares EMM, Lemos TMAM, Maranhão TMO, Azevedo GD. Índices de obesidade central e fatores de risco cardiovascular na síndrome dos ovários policísticos. Arq Bras Cardiol. 2010; 94(5):633-8.

7. Chen MJ, Yang WS, Yang JH, Chen CL, Ho HN, Yang YS. Relationship between androgen levels and blood pressure in young women with polycystic ovary syndrome. Hypertension. 2007; 49(6):1442-7.

8. Rocha Gontijo JA, Gui DC, Boer PA, Dos Santos AR, Ferreira-Filho CP, Nery Aguiar AR, et al. Evaluation of arterial blood pressure and renal sodium handling in a model of female rats in persistent estrus. Clin Exp Hypertens. 2010; 32(6):385-9.

9. Palomba S, Santagni S, Falbo A, La Sala GB. Complications and challenges associated with polycystic ovary syndrome: current perspectives. Int J Womens Health. 2015; 7:745-63.

10. Bentley-Lewis R, Seely E, Dunaif A. Ovarian hypertension: polycystic ovary syndrome. Endocrinol Metab Clin North Am. 2011; 40(2):433-49.

11. Melo AS, Dias SV, Cavalli RC, Cardoso VC, Bettiol H, Barbieri MA, et al. Pathogenesis of polycystic ovary syndrome: multifactorial assessment from the foetal stage to menopause. Reproduction. 2015; 150(1):R11-24.

12. Sóter MO, Ferreira CN, Sales MF, Candido AL, Reis FM, Milagres KS, et al. Peripheral blood-derived cytokine gene polymorphisms and metabolic profile in women with polycystic ovary syndrome. Cytokine. 2015; 76(2):227-35.

13. Demissie M, Lazic M, Foecking EM, Aird F, Dunaif A, Levine JE. Transient prenatal androgen exposure produces metabolic syndrome in adult female rats. Am J Physiol Endocrinol Metab. 2008; 295(2):E262-8.

14. Dumesic DA, Oberfield SE, Stener-Victorin E, Marshall JC, Laven JS, Legro RS. Scientific statement on the diagnostic criteria, epidemiology, pathophysiology, and molecular genetics of polycystic ovary syndrome. Endocr Rev. 2015; 36(5):487525 .

15. Witchel SF, Recabarren SE, González F, Diamanti-Kandarakis E, Cheang KI, Duleba AJ, et al. Emerging concepts about prenatal genesis, aberrant metabolism and treatment paradigms in polycystic ovary syndrome. Endocrine. 2012; 42(3):526-34.

16. King J. Polycystic ovary syndrome. J Midwifery Womens Health. 2006; 51(6):415-22.

17. Erhmann DA. Polycystic ovary syndrome. N Engl J Med. 2005; 352(12):1223-36.

18. da Silva BB, Lopes-Costa PV, Rosal MA, dos Santos LG, Gontijo JA, Alencar $\mathrm{AP}$, et al. Morphological and morphometric analysis of the adrenal cortex of androgenized female rats. Gynecol Obstet Invest. 2007; 64(1):44-8.

19. Dunaif A. Insulin resistance and the polycystic ovary syndrome: mechanism and implications for pathogenesis. Endocr Rev. 1997; 18(6):774-800.

20. Dumitrescu R, Mehedintu C, Briceag I, Purcarea VL, Hudita D. The polycystic ovary syndrome: an update on metabolic and hormonal mechanisms. J Med Life. $2015 ; 8(2): 142-5$.

21. Ikeda K, Baba T, Morishita M, Honnma H, Endo T, Kiya T, et al. Long-term treatment with dehydroepiandrosterone may lead to follicular atresia through interaction with anti-Mullerian hormone. J Ovarian Res. 2014; 7:46.

22. Azziz R. Diagnostic criteria for polycystic ovary syndrome: a reappraisal. Fertil Steril. 2005; 83(5):1343-6.

23. Legro RS, Arslanian SA, Ehrmann DA, Hoeger KM, Murad MH, Pasquali $\mathrm{R}$, et al. Diagnosis and treatment of polycystic ovary syndrome: an Endocrine Society clinical practice guideline. J Clin Endocrinol Metab. 2013; 98(12):456592.

24. Tsikouras P, Spyros L, Manav B, Zervoudis S, Poiana C, Nikolaos T, et al. Features of polycystic ovary syndrome in adolescence. J Sex Med. 2015; $8(3): 291-6$

25. Hsu M. Clinical characteristics in Taiwanese women with polycystic ovary syndrome. Clin Exp Reprod Med. 2015; 42(3):86-93.

26. Tosi F, Fiers T, Kaufman J, Dall'Alda M, Moretta R, Giagulli VA, et al. Implications of androgen assay accuracy in the phenotyping of women with polycystic ovary syndrome. J Clin Endocrinol Metab. 2016; 101(2):610-8.

27. Escobar-Morreale HF, Carmina E, Dewailly D, Gambineri A, Kelestimur F, Moghetti P, et al. Epidemiology, diagnosis and managem hirsutism: a 
consensus statement by the Androgen Excess and Polycystic Ovary Syndrome Society. Hum Reprod Update. 2012; 18(2):146-70.

28. Lenart-Lipi冈ska M, Matyjaszek-Matuszek B, Wo囚niakowska E, Solski J, Tarach JS, Paszkowski T. Polycystic ovary syndrome: clinical implication in perimenopause. Prz Menopauzalny. 2014; 13(6):348-51.

29. Stener-Victorin E, Ploj K, Larsson B, Holmäng A. Rats with steroid-induced polycystic ovaries develop hypertension and increased sympathetic nervous system activity. Reprod Biol Endocrinol, 2005; 3:44.

30. Kargili A, Karakurt F, Kasapoglu B, Derbent A, Koca C, Selcoki Y. Association of polycystic ovary syndrome and a non-dipping blood pressure pattern in young women. Clinics. 2010; 65(5):475-9.

31. Holte J, Gennarelli G, Berne C, Bergh T, Lithell H. Elevated ambulatory daytime blood pressure in women with polycystic ovary syndrome: a sign of a pre-hypertensive state? Hum Reprod. 1996; 11(1):23-8.

32. Wild RA, Carmina E, Diamanti-Kandarakis E, Dokras A, Escobar-Morreale HF, Futterweit W, et al. Assessment of cardiovascular risk and prevention of cardiovascular disease in women with the polycystic ovary syndrome: a consensus statement by the Androgen Excess and Polycystic Ovary Syndrome (AE-PCOS) Society. J Clin Endocrinol Metab. 2010; 95(5):2038-49.

33. Gambineri A, Pelusi A, Vicennati V, Pagotto U, Pasquali R. Obesity and the polycystic ovary syndrome. Int J Obes Relat Metab Disord. 2002; 26(7):883-96.
34. Cho LW, Randeva HS, Atkin, SL. Cardiometabolic aspects of polycystic ovarian syndrome. Vasc Health Risk Manag. 2007; 3(1):55-63.

35. Abransom BL, Melvin RG. Cardiovascular risk in women: focus on hypertension. Can J Cardiol. 2014; 30(5):553-9.

36. Walters KA, Allan CM, Handelsman DJ. Rodent models for human polycystic ovary syndrome. Biol Reprod. 2012; 86(5):149, 1-12.

37. Singh KB. Persistent estrus rat models of polycystic ovary disease: an update. Fertil Steril. 2005; 84(2):1228-34.

38. Russo J, Russo IH. Biology of disease: biological and molecular bases of mammary carcinogenesis. Lab Invest. 1987; 57(2):112-37.

39. Barraclough CA. Production of anovulation, sterile rats by single injection of testosterone propionate. Endocrinology. 1961; 68:62-7.

40. Wang F, Yu B, Yang W, Liu J, Lu J, Xia X. Polycystic ovary syndrome resembling histopathological alterations in ovaries from prenatal androgenized female rats. J Ovarian Res. 2012; 5(1):15.

41. Heald PJ, O'Gray JE, Howie AJ. Quantitative changes in uterine nucleic acids during the oestrous cycle in rats. J Reprod Fertil. 1970; 21(3):481-8.

42. Ramezani Tehrani F, Noroozzadeh M, Zahediasl S, Piryaei A, Hashem $\mathrm{S}$, Azizi F. The time of prenatal androgen exposure affects development of polycystic ovary syndrome-like phenotype in adulthood in female rats. Int J Clin Endocrinol Metab. 2014; 12(2):e16502 